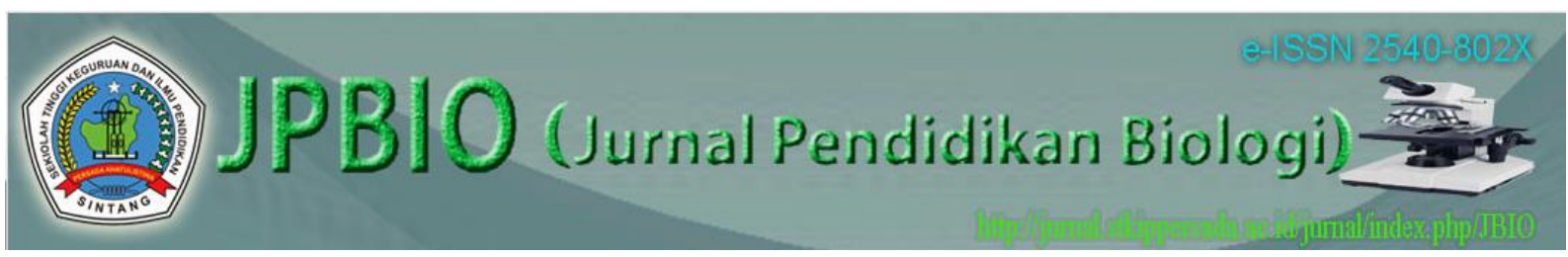

JPBIO (Jurnal Pendidikan Biologi)

Vol. 1 No. 1 November $2016 \mid 40-50$

ISSN 2540-802x (Online)

DOI: http://dx.doi.org/10.31932/ JPBIO (Jurnal Pendidikan Biologi)

http://jurnal.stkippersada.ac.id/jurnal/index.php/JBIO

\title{
PENERAPAN METODE PEMBELAJARAN INSIDE OUTSIDE CIRCLE UNTUK MENINGKATKAN AKTIVITAS BELAJAR DAN HASIL BELAJAR KOGNITIF SISWA PADA MATERI KESEIMBANGAN EKOSISTEM
}

\author{
Edi Saroyo ${ }^{1^{*}}$, Didin Syafruddin ${ }^{2^{*}}$, Markus lyus Supiandi ${ }^{3}$ \\ 1Mahasiswa Program Studi Pendidikan Biologi, STKIP Persada Khatulistiwa Sintang \\ 2,3Dosen Program Studi Pendidikan Biologi, STKIP Persada Khatulistiwa Sintang \\ E-mail: ediroy643@gmail.com,didin_saprudin28@yahoo.com*, \\ msupiandi@gmail.com
}

Diterima: 28 April 2016

Direvisi: 29 Mei 2016

Disetujui: 27 Oktober 2016

\begin{abstract}
ABSTRAK
Tujuan penelitian ini adalah untuk meningkatkan aktivitas belajar dan hasil belajar kognitif. Bentuk penelitian ini adalah penelitian tindakan kelas. Subjek penelitian adalah siswa kelas VI Sekolah Dasar Negeri 35 Sempulau Indah yang berjumlah 24 siswa. Untuk mengumpulkan data digunakan lembar observasi, soal tes dan lembar angket respon siswa. Hasil penelitian menunjukan bahwa metode pembelajaran Inside Outside Circle dapat meningkatkan aktivitas belajar dan hasil belajar kognitif siswa. Aktivitas belajar siswa pada siklus I pertemuan pertama pada indikator visual $89,58 \%$, lisan $54,17 \%$, mendengarkan $83,33 \%$ dan emosional $86,11 \%$. Pada pertemuan kedua indikator visual $91,67 \%$, lisan $56,94 \%$, mendengarkan $83,33 \%$ dan emosional $84,44 \%$. Pada siklus II pertemuan pertama indikator visual $95,83 \%$, lisan $72,22 \%$, mendengarkan $89,58 \%$ dan emosional $98,61 \%$. Pada pertemua kedua indikator visual 100\%, lisan $80,55 \%$, mendengarkan $97,91 \%$ dan emosional $100 \%$. Sedangkan hasil belajar kognitif siswa pada siklus I diperoleh nilai rata-rata 77,91 dan pada siklus II diperoleh nilai rata-rata sebesar 84,58 sehingga diperoleh peningkatan ratarata sebesar 6,87 . Sehingga dapat disimpulkan bawa terdapat peningkatan aktivitas belajar dan hasil belajar kognitif siswa dengan menggunakan metode pembelajaran Inside Outside Circle.
\end{abstract}

Kata kunci: metode inside outside circle, aktivitas belajar, hasil belajar kognitif

\section{ABSTRACT}

The purpose of this research is to increase the students' learning activity and the cognitive learning. Form of this research is a classroom action research. The subject of this research was students of Grade VI State Elementary School 35 Sempulau Indah totaling to 24 students. Furthermore, the data collection tolls used was observation sheet, questions test and student questionnaire responses sheet. Results the research showed that Inside Outside Circle learning methods can increase the students' learning activity and their cognitive learning outcomes also increased. Students activities in the first meeting of the first cycle on indicator of visual was $89.58 \%$, verbal $54.17 \%$, emotional $83.33 \%$ and listening $86.11 \%$. At 
the second meeting, the visual indicator $91.67 \%$, verbal $56.94 \%$, emotional $83.33 \%$ and listening $84.44 \%$. Meanwhile, at the first meeting of the second cycle the visual indicator was $95.83 \%$, verbal $72.22 \%$, emotional $89.58 \%$ and listening $98.61 \%$. While, at the second cycle visual indicators $100 \%$, verbal $80.55 \%$, emotional $97.91 \%$ and listening was $100 \%$. While, the cognitive achievement of students in the first cycle obtained by the average value 77.91 and at the second cycle obtained an average values as 84.58 thus, obtain an average increase as 6.87. Therefore, it can be concluded that the application of Inside Outside Circle learning methods increased the students' learning activity and the cognitive learning outcomes.

Keywords: inside outside circle method, learning activities, cognitive learning outcomes

\section{PENDAHULUAN}

Pendidikan pada hakikatnya adalah usaha membudayakan manusia atau memanusiakan manusia. Dengan kata lain, usaha agar manusia dapat mengembangkan potensi dirinya melalui proses pembelajaran atau dengan cara lain yang dikenal dan diakui oleh masyarakat. Hal ini seperti yang di tuangkan dalam Undang-undang Nomor 20 Tahun 2003 tentang sistem Pendidikan Nasional (2003 : 3) menyatakan bahwa:

Pendidikan adalah usaha sadar dan terencana untuk mewujudkan suasana belajar dan proses pembelajaran agar peserta didik secara aktif mengembangkan potensi dirinya untuk memiliki kekuatan spiritual keagamaan, pengendalian diri, kepribadian, kecerdasan, akhlak mulia, serta keterampilan yang diperlukan dirinya, masyarakat, bangsa dan Negara.

Amanat undang-undang tersebut mengindikasikan bahwa dalam kehidupan manusia membutuhkan pendidikan.Melalui pendidikan manusia dapat mengembangkan potensi dirinya agar taraf hidup bangsa Indonesia tidak sampai tertinggal dari bangsa lain. Karena proses pendidikan merupakan proses belajar dan pembelajaran.

Proses pembelajaran yang terjadi dalam dunia pendidikan adalah proses interaksi antara guru dan siswa serta siswa dan siswa. Berhasil tidaknya proses pembelajaran berhubungan dengan bagaimana interaksi antara guru dan siswa serta siswa dan siswa tersebut. Interaksi yang dibangun merupakan usaha yang dilakukan oleh guru untuk mendapatkan umpan balik dari siswa dalam pola pembelajaran. Dalam pembelajaran itu sendiri guru harus mampu menghidupkan motivasi siswa dalam belajar baik melalui cara mengelola kelas dan cara mengajar pada semua mata pelajaran tidak terkecuali mata pelajaran IPA.

Pelajaran IPA merupakan mata pelajaran yang juga harus dikuasai oleh para siswa. Mengingat pelajaran IPA didalamnya terdapat beraneka ragam materi-materi yakni yang menyangkut dengan apa yang ada di lingkungan sekitar, mempelajari proses pertumbuhan pada mahluk hidup, dan juga organ yang ada pada manusia. Jadi, dengan mempelajari banyak hal yang ada di mata pelajaran IPA, kita dapat mengetahui mengenai lingkungan sekitar, organ tubuh pada manusia, keseimbangan ekosistem dan lain sebagainya.

Materi keseimbangan ekosistem merupakan salah satu materi yang diajarkan pada mata pelajaran IImu Pengetahuan Alam khususnya di kelas VI. Jadi dengan adanya Pelajaran IPA dapat membantu para siswa untuk berpola pikir ilmiah, yakni menelusuri langsung apa yang ada di lingkungan sekitar sehingga ketika siswa melakukan observasi atau penelitian, siswa dapat menemukan bukti-bukti yang konkrit di lapangan.

Aktivitas belajar merupakan segala kegiatan yang dilakukan dalam proses interaksi (guru dan siswa) dalam rangka mencapai tujuan belajar. Sardiman dalam Wira (2012) menyatakan "Aktivitas belajar merupan prinsip atau azas yang sangat penting di dalam interaksi belajar mengajar". Aktivitas yang dimaksud disini penekanannya adalah pada siswa, sebab dengan adanya aktivitas siswa dalam proses pembelajaran terciptalah situasi belajar yang aktif. Tanpa adanya aktivitas maka proses belajar mengajar tidak akan berjalan dengan baik.

Berdasarkan pra observasi yang dilakukan pada tanggal 24 Maret 2016 dan atas izin Kepala Sekolah serta wawancara yang dilakukan bersama guru kelas VI SD Negeri 35 Sempulau Indah menyatakan bahwa masih banyak siswa yang kurang aktif dalam proses 
pembelajaran dan mendapat hasil belajar yang kurang baik pada mata pelajaran IImu Pengetahuan Alam. Kurangnya aktivitas belajar siswa dalam hal ini dapat dilihat dalam proses pembelajaran yang mana siswa kurang termotivasi dan tidak aktif dalam belajar, hal ini terlihat dari kurangnya perhatian siswa dalam mengikuti pelajaran, siswa tidak belajar mandiri, siswa keluar masuk kelas dan siswa kurang serius dalam mengerjakan tugas yang diberikan. Permasalahan ini tidak terlepas dari penyajian materi pelajaran yang pada umumnya guru lebih sering berceramah dan jarang menggunakan media atau model pembelajaran sehingga proses pembelajaran terpusat pada guru saja.

Guru lebih banyak menggunakan waktu untuk menjelaskan materi pelajaran, sehingga siswa jarang diberikan kesempatan untuk menemukan dan mengembangkan kemampuan berpikir dalam mengembangkan pengetahuan dan pengalaman belajarnya. Dalam proses pembelajaran biologi sebaiknya guru tidak hanya menyampaikan materi dengan metode ceramah, tetapi membantu siswa berkomunikasi (mengungkapkan ide), memecahkan masalah dan membentuk pengetahuan sendiri.

Sutikno (2009: 95) menyatakan bahwa "Pembelajaran dengan menggunakan metode ceramah, perhatian hanya berpusat kepada guru sedangkan para siswa hanya menerima secara pasif, mirip anak balita yang sedang disuapi”. Dalam hal ini, timbul kesan bahwa siswa hanya sebagai objek yang selalu menganggap benar apa yang disampaikan guru. Proses pembelajaran yang demikian akan berdampak pada hasil belajar siswa yang kurang baik. Dalam hal ini seharusnya guru dapat membuat siswa lebih aktif dalam pembelajaran

Sedangkan hasil belajar siswa yang rendah terlihat dari hasil belajar siswa dengan Kriterian Ketuntasan Minimal (KKM) 65 pada mata pelajaran IImu Pengetahuan Alam yang masih banyak tidak tuntas. Dari 28 siswa, siswa yang tuntas pada mata pelajaran IImu Pengetahuan Alam sebanyak 13 siswa, sedangkan yang tidak tuntas sebanyak 15 siswa. $\mathrm{Hal}$ ini disebabkan kurangnya penggunaan metode atau model pembelajaran yang berfariasi oleh guru sehinggamasih banyak siswa yang mendapatkan nilai rendah setiap diberi soal latihan.

Berdasarkan permasalahan-permasalahan di atas, seharusnya guru dapat menyampaikan materi ajar dengan menggunakan metode ataupun model pembelajaran yang bervariasi sehingga nantinya siswa dapat berpartisipasi aktif didalam proses belajar mengajar dan mendapat nilai yang bagus. Salah satu model pembelajaran yang dapat digunakan agara siswa lebih aktif dalam belajar adalah dengan menggunakan metode pembelajaran Inside Outside Circle (IOC).

Metode pembelajaran Inside Outside Circle (IOC) adalah sebuah metode pembelajaran yang memungkinkan siswa untuk melatih kemampuan komunikasi siswa.Ngalimun, (2016: 241) juga menyatakan bahwa "Metode pembelajaran Inside Outside Circle(IOC) adalah sebuah metode pembelajaran dengan sistem lingkaran kecil dan lingkaran besar. Dimana siswa saling memberi informasi pada saat yang bersamaan dengan pasangan yang berbeda dengan singkat dan teratur".

Berdasarkan masalah yang ada pada siswa kelas VI SD Negeri 35 Sempulau Indah, peneliti tertarik untuk melakukan penelitan tindakan kelas tentang penggunaan metode pembelajaran Inside Outside Circle (IOC) pada mata pelajaran IImu Pengetahuan Alam. Oleh karena itu, peneliti akan meneliti tentang "Penerapan metode pembelajran Inside Outside Circle (IOC) untuk meningkatkan aktivitas belajar dan hasil belajar kognitif siswa pada materi keseimbangan ekosistem pada siswa kelas VI Sekolah Dasar Negeri 35 Sempulau Indah Tahun Ajaran 2016/2017"

\section{METODE PENELITIAN}

Sugiyono, (2014: 6) menyatakan bahwa "Metode penelitian pendidikan dapat diartikan sebagai cara ilmiah untuk mendapatkan data yang valid dengan tujuan dapat ditemukan, dikembangkan, dan dibuktikan, suatu pengetahuan tertentu sehingga pada gilirannya dapat digunakan untuk memahami, memecahkan dan mengantisipasi masalah dalam bidang pendidikan".

Metode yang digunakan dalam penelitian ini adalah metode penelitian kualitatif. Sugiyono, (2014: 15) menyatakan bahwa "Metode penelitian kualitatif adalah metode 
penelitian yang berlandaskan pada filsafat postpositivisme, digunakan untuk meneliti pada kondisi obyek yang alamiah, dimana peneliti adalah sebagi instrumen kunci, pengambilan sampel sumber data dilakukan secara purposive dan snowbaal, teknik pengumpulan dengan trianggulasi (gabungan), analisis data bersifat induktif/kualitatif, dan hasil penelitiankualitatif lebih menekankan makna dari pada generalisai".

\section{HASIL PENELITIAN}

Untuk melihat hasil kegiatan guru dalam menerapkan metode pembelajran Inside Outside Circle (IOC), dapat dilihat pada Tabel sebagai berikut:

Tabel 1. Kegiatan guru dalam melaksanakanmetode pembelajran Inside Outside Circle (IOC) pada siklus I dan II.

\begin{tabular}{c|c|c|c|c|c|c}
\hline \multirow{2}{*}{ No } & \multirow{2}{*}{ Siklus } & \multirow{2}{*}{ Pertemuan } & \multicolumn{2}{|c|}{ Javiban } & \multirow{2}{*}{$\%$} & \multirow{2}{*}{ Keterangan } \\
\cline { 4 - 7 } & & & Ya & Tidak & & \\
\hline 1 & I & 1 & 18 & 2 & 90 & Sangat Baik \\
\hline 2 & I & 2 & 19 & 1 & 95 & Sangat Baik \\
\hline 3 & II & 1 & 19 & 1 & 95 & Sangat Baik \\
\hline 4 & II & 2 & 20 & 0 & 100 & Sangat Baik \\
\hline
\end{tabular}

Berdasarkan Tabel di atas dapat simpulkan bahwa kegiatan guru dalam melaksanakan pembelajaran dengan menggunakan Metode Pembelajaran Inside Outside Circle (IOC) pada materi keseimbangan ekosistem pada siswa kelas VI Sekolah Dasar Negeri 35 Sempulau Indah. Pada siklus I pertemuan pertama diperoleh persentasi 90\%, siklus I pertemuan kedua 95\%, siklus II pertemuan pertama 95\% dan siklus II pertemuan kedua $100 \%$ mengalami peningkatan yang sangat signifikan dan dapat dikatakan sangat baik.

Untuk melihat kegiatan siswa dalam mengikuti pembelajaran dengan menggunakan metode mpembelajaran Inside Outside Circle (IOC), dapat dilihat pada Tabel sebagai berikut:

Tabel 2. Kegiatan siswa dalam mengikuti pembelajaran dengan menggunakanmetode pembelajran Inside Outside Circle (IOC) pada siklus I dan II.

\begin{tabular}{c|c|c|c|c|c|c}
\hline \multirow{2}{*}{ No } & \multirow{2}{*}{ Siklus } & \multirow{2}{*}{ Pertemuan } & \multicolumn{2}{|c|}{ Jawaban } & \multirow{2}{*}{$\%$} & \multirow{2}{*}{ Keterangan } \\
\cline { 3 - 6 } & & Ya & Tidak & & \\
\hline 1 & I & 1 & 14 & 2 & 87,50 & Sangat Baik \\
\hline 2 & I & 2 & 15 & 1 & 93,75 & Sangat Baik \\
\hline 3 & II & 1 & 15 & 1 & 93,75 & Sangat Baik \\
\hline 4 & II & 2 & 16 & 0 & $\mathbf{1 0 0}$ & Sangat Baik \\
\hline
\end{tabular}

Berdasarkan Tabel di atas dapat simpulkan bahwa kegiatan siswa pada saat mengikuti pembelajaran dengan menggunakan Metode Pembelajaran Inside Outside Circle (IOC)pada materi keseimbangan ekosistem, Pada siklus I pertemuan pertama diperoleh persentasi $87,50 \%$, siklus I pertemuan kedua 93,75\%, siklus II pertemuan pertama 93,75\% dan siklus II pertemuan kedua $100 \%$ mengalami peningkatan yang sangat signifikan dan dapat dikatakan sangat baik. Untuk melihat aktivitas siswa dalam mengikuti pembelajaran dapat di lihat pada Tabel sebagai berikut:

Tabel 3. Aktivitas belajar siswasetiap indikator pada siklus $ل$ dan $ل$.

\begin{tabular}{|c|c|c|c|c|c|c|}
\hline \multirow{2}{*}{ Indikator } & \multirow{2}{*}{ Siklus } & \multirow[t]{2}{*}{ Pertemuan } & \multicolumn{2}{|c|}{$\begin{array}{c}\text { Persentasi } \\
(\%)\end{array}$} & \multicolumn{2}{|c|}{ Rata-rata } \\
\hline & & & $Y \mathbf{Y a}$ & Tidak & $\mathbf{Y a}$ & Tidak \\
\hline \multirow{4}{*}{ Visual } & \multirow[b]{2}{*}{ I } & 1 & 89.58 & 10,42 & \multirow{2}{*}{90,62} & \multirow{2}{*}{9.38} \\
\hline & & 2 & 91,67 & 8,33 & & \\
\hline & \multirow{2}{*}{ II } & 1 & 95,83 & 4.17 & \multirow{2}{*}{97,91} & \multirow{2}{*}{2,09} \\
\hline & & 2 & 100 & $\mathrm{O}$ & & \\
\hline \multirow{4}{*}{ Oral } & \multirow{2}{*}{ I } & 1 & 54,17 & 45.83 & \multirow{2}{*}{55.55} & \multirow{2}{*}{44,45} \\
\hline & & 2 & 56,94 & 43,06 & & \\
\hline & \multirow{2}{*}{ II } & 1 & 72,22 & 27,78 & \multirow{2}{*}{78,38} & \multirow{2}{*}{23,62} \\
\hline & & 2 & 80,55 & 19,45 & & \\
\hline \multirow{4}{*}{ Listening } & \multirow[b]{2}{*}{ I } & 1 & 83,33 & 16,67 & \multirow{2}{*}{83,33} & \multirow{2}{*}{16,67} \\
\hline & & 2 & 83,33 & 16,67 & & \\
\hline & \multirow{2}{*}{ II } & 1 & 89,58 & 10,42 & \multirow{2}{*}{93,74} & \multirow{2}{*}{6,26} \\
\hline & & 2 & 97,91 & 2,09 & & \\
\hline \multirow{4}{*}{ Emotional } & \multirow{2}{*}{ I } & 1 & 86,11 & 13,89 & \multirow{2}{*}{85,27} & \multirow{2}{*}{14,73} \\
\hline & & 2 & 84,44 & 15,56 & & \\
\hline & \multirow{2}{*}{ II } & 1 & 98,61 & 1,39 & \multirow{2}{*}{99,30} & \multirow{2}{*}{0,70} \\
\hline & & 2 & 100 & $\mathrm{O}$ & & \\
\hline
\end{tabular}


Berdasarkan Tabel diatas terlihat bahwa pada siklus I pertemuan pertama, hasil observasi aktivitas belajar siswa untuk yang menjawab "Ya" pada indikator visual activities sebesar $89,58 \%$ dan yang menjawab "Tidak" sebesar 10,42\%. Untuk indikator oral activities yang menjawab "Ya" sebesar $54,17 \%$ dan yang menjawab "Tidak" sebesar $45,85 \%$. Untuk indikator listening activities yang menjawab "Ya" sebesar $83,33 \%$ dan yang menjawab "Tidak" sebesar 16,67\%. Untuk indikator emotional activities yang menjawab "Ya" sebesar $86,11 \%$ dan yang menjawab "Tidak" sebesar $13,89 \%$. Selanjutnya pada siklus I pertemuan kedua hasil observasi aktivitas belajar siswa untuk yang menjawab "Ya" pada indikator visual activities sebesar $91,67 \%$ dan yang menjawab "Tidak" sebesar $8,33 \%$. Untuk indikator oral activities yang menjawab "Ya" sebesar $56,94 \%$ dan yang menjawab "Tidak" sebesar 43,06\%. Untuk indikator listening activities yang menjawab "Ya" sebesar 83,33\% dan yang menjawab "Tidak" sebesar 16,67\%. Untuk indikator emotional activities yang menjawab "Ya" sebesar $84,44 \%$ dan yang menjawab "Tidak" sebesar 10,56\%.

Berdasarkan hasil observasi aktivitas belajar siswa pada siklus II pertemuan pertama untuk yang menjawab "Ya" pada indikator visual activities sebesar 95,83\% dan yang menjawab "Tidak" sebesar $4,17 \%$. Untuk indikator oral activities yang menjawab "Ya" sebesar $72,22 \%$ dan yang menjawab "Tidak" sebesar $27,78 \%$. Untuk indikator listening activities yang menjawab "Ya" sebesar $89,58 \%$ dan yang menjawab "Tidak" sebesar 10,42\%. Untuk indikator emotional activities yang menjawab "Ya" sebesar 98,61\% dan yang menjawab "Tidak" sebesar 1,39\%. Selanjutnya pada siklus II pertemuan kedua hasil observasi aktivitas belajar siswa untuk yang menjawab "Ya" pada indikator visual activities sebesar $100 \%$ dan yang menjawab "Tidak" sebesar $0 \%$. Untuk indikator oral activities yang menjawab "Ya" sebesar 80,55\% dan yang menjawab "Tidak" sebesar 19,45\%. Untuk indikator listening activities yang menjawab "Ya" sebesar $97,91 \%$ dan yang menjawab "Tidak" sebesar 2,09\%. Untuk indikator emotional activities yang menjawab "Ya" sebesar $100 \%$ dan yang menjawab "Tidak" sebesar 0\%. Untuk melihat hasil belajar siswa dapat dilihat pada Tabel sebagai berikut:

Tabel 4. Hasil Analisis Soal Tes Jenjang Pengetahuan Siklus I

\begin{tabular}{|c|c|c|c|c|c|c|}
\hline \multirow{2}{*}{ Siklus } & \multirow{2}{*}{ Skor } & \multicolumn{3}{|c|}{ Nomor Soal } & \multirow{2}{*}{ Jumlah } & $\begin{array}{c}\text { Persentasi } \\
\text { (\%) }\end{array}$ \\
\cline { 2 - 7 } & & 1 & 2 & 3 & & 84,72 \\
\hline \multirow{3}{*}{1} & 10 & 17 & 24 & 20 & 61 & 5,56 \\
\cline { 2 - 7 } & 5 & 3 & 0 & 1 & 4 & 5 \\
\cline { 2 - 7 } & 0 & 4 & 0 & 3 & 7 & 9,72 \\
\hline
\end{tabular}

Tabel 5. Hasil Analisis Soal Tes Jenjang Pemahaman Siklus I

\begin{tabular}{|c|c|c|c|c|}
\hline Siklus & Skor & $\frac{\text { Nomor Soal }}{4}$ & Jumlah & $\begin{array}{c}\text { Persentasi } \\
(\%)\end{array}$ \\
\hline \multirow{3}{*}{1} & 10 & 22 & 22 & 91,66 \\
\hline & 5 & 1 & 1 & 4,17 \\
\hline & 0 & 1 & 1 & 4,17 \\
\hline
\end{tabular}

Tabel 6. Hasil Analisis Soal Tes Jenjang Aplikasi Siklus I

\begin{tabular}{|c|c|c|c|c|}
\hline Siklus & Skor & $\frac{\text { Nomor Soal }}{4}$ & Jumlah & $\begin{array}{c}\text { Persentasi } \\
(\%)\end{array}$ \\
\hline \multirow{3}{*}{1} & 10 & 10 & 10 & 41,67 \\
\hline & 5 & 4 & 4 & 16,67 \\
\hline & 0 & 10 & 10 & 41,67 \\
\hline
\end{tabular}


Tabel 7. Hasil Analisis Soal Tes Jenjang Analisis Siklus I

\begin{tabular}{|c|c|c|c|c|c|}
\hline \multirow{2}{*}{ Siklus } & \multirow{2}{*}{ Skor } & \multicolumn{2}{|c|}{ Nomor Soal } & \multirow{2}{*}{ Jumlah } & \multirow{2}{*}{$\begin{array}{c}\text { Persentasi } \\
(\%)\end{array}$} \\
\hline & & 6 & 9 & & \\
\hline \multirow{3}{*}{1} & 10 & 23 & 9 & 32 & 66,67 \\
\hline & 5 & 0 & 4 & 4 & 8,33 \\
\hline & 0 & 1 & 10 & 11 & 22,92 \\
\hline
\end{tabular}

Tabel 8. Hasil Analisis Soal Tes Jenjang Sintesis Siklus I

\begin{tabular}{|c|c|c|c|c|c|}
\hline \multirow{2}{*}{ Siklus } & \multirow{2}{*}{ Skor } & \multicolumn{2}{|c|}{ Nomor Soal } & \multirow{2}{*}{ Jumlah } & $\begin{array}{c}\text { Persentasi } \\
\text { (\%) }\end{array}$ \\
\cline { 3 - 6 } & & $\mathbf{5}$ & $\mathbf{7}$ & & 68,75 \\
\hline \multirow{3}{*}{1} & 10 & 16 & 17 & 33 & 68,83 \\
\hline & 5 & 5 & 5 & 10 & 20,83 \\
\hline & 0 & 3 & 2 & 5 & 10,42 \\
\hline
\end{tabular}

Tabel 9. Hasil Analisis Soal Tes Jenjang Evaluasi Siklus I

\begin{tabular}{|c|c|c|c|c|}
\hline \multirow{2}{*}{ Siklus } & Skor & \begin{tabular}{c} 
Nomor Soal \\
\cline { 3 - 5 } Jumlah
\end{tabular} & $\begin{array}{c}\text { Persentasi } \\
\mathbf{( \% )}\end{array}$ \\
\hline \multirow{3}{*}{1} & 10 & 17 & 17 & 70,83 \\
\hline & 5 & 0 & 0 & 0 \\
\hline & 0 & 7 & 7 & 29,17 \\
\hline
\end{tabular}

Tabel 9. Rekapitulasi Hasil Tes Siklus I

\begin{tabular}{|l|l|c}
\hline No & Keterangan & Nilai \\
\hline 1 & Nilai Tertinggi & 95 \\
\hline 2 & Nilai Terendah & 40 \\
\hline 3 & Nilai Rata-rata & 77,91 \\
\hline 4 & Ketuntasan Klasikal & 83,33 \\
\hline
\end{tabular}

Berdasarkan Tabel di atas dapat disimpulkan bahwa hasil belajar siswa pada siklus I dengan jumlah siswa 24 orang, siswa tuntas sebanyak 20 orang dan siswa tidak tuntas sebanyak 4 orang diperoleh nilai rata-rata sebesar 77,91.

Tabel 10. Hasil Analisis Soal Tes Jenjang Pengetahuan Siklus II

\begin{tabular}{c|c|c|c|c|c|c|c}
\hline \multirow{2}{*}{ Siklus } & \multirow{2}{*}{ Skor } & \multicolumn{4}{|c|}{ Nomor Soal } & \multirow{2}{*}{ Jumlah } & $\begin{array}{c}\text { Persentasi } \\
\text { (\%) }\end{array}$ \\
\cline { 3 - 7 } & & 1 & 2 & 4 & 5 & & 78,13 \\
\hline \multirow{2}{*}{ II } & 10 & 16 & 18 & 24 & 17 & 75 & 17,70 \\
\cline { 2 - 6 } & 5 & 7 & 4 & 0 & 6 & 17 & 17 \\
\cline { 2 - 6 } & 0 & 1 & 2 & 0 & 1 & 4 & 4,17 \\
\hline
\end{tabular}

Tabel 11. Hasil Analisis Soal Tes Jenjang Pemahaman Siklus II

\begin{tabular}{|c|c|c|c|c|}
\hline Siklus & Skor & $\frac{\text { Nomor Soal }}{3}$ & Jumlah & $\begin{array}{c}\text { Persentasi } \\
(\%)\end{array}$ \\
\hline \multirow{3}{*}{ II } & 10 & 20 & 20 & 83,33 \\
\hline & 5 & 4 & 4 & 16,67 \\
\hline & 0 & 0 & 0 & 0 \\
\hline
\end{tabular}


Tabel 12. Hasil Analisis Soal Tes Jenjang Aplikasi Siklus II

\begin{tabular}{|c|c|c|c|c|}
\hline Siklus & Skor & $\frac{\text { Nomor Soal }}{8}$ & Jumlah & $\begin{array}{c}\text { Persentasi } \\
(\%)\end{array}$ \\
\hline \multirow{3}{*}{ II } & 10 & 23 & 23 & 95,83 \\
\hline & 5 & 0 & 0 & 0 \\
\hline & 0 & 1 & 1 & 4,17 \\
\hline
\end{tabular}

Tabel 13. Hasil Analisis Soal Tes Jenjang Analisis Siklus II

\begin{tabular}{|c|c|c|c|c|c|}
\hline \multirow{2}{*}{ Siklus } & \multirow{2}{*}{ Skor } & \multicolumn{2}{|c|}{ Nomor Soal } & \multirow{2}{*}{ Jumlah } & $\begin{array}{c}\text { Persentasi } \\
\text { nyyynd }\end{array}$ \\
\cline { 3 - 6 } & & $\mathbf{7}$ & $\mathbf{9}$ & & 52,08 \\
\hline \multirow{2}{*}{ II } & 10 & 24 & 1 & 25 & 35,42 \\
\cline { 2 - 6 } & 5 & 0 & 17 & 17 & 12,5 \\
\hline
\end{tabular}

Tabel 14. Hasil Analisis Soal Tes Jenjang Sintesis Siklus II

\begin{tabular}{|c|c|c|c|c|}
\hline Siklus & Skor & $\frac{\text { Nomor Soal }}{3}$ & Jumlah & $\begin{array}{c}\text { Persentasi } \\
(\%)\end{array}$ \\
\hline \multirow{3}{*}{ II } & 10 & 23 & 23 & 95,83 \\
\hline & 5 & 0 & 0 & 0 \\
\hline & 0 & 1 & 1 & 4,17 \\
\hline
\end{tabular}

Tabel 15. Hasil Analisis Soal Tes Jenjang Evaluasi Siklus II

\begin{tabular}{|c|c|c|c|c|}
\hline \multirow{2}{*}{ Siklus } & \multirow{2}{*}{ Skor } & $\begin{array}{c}\text { Nomor } \\
\text { Soal }\end{array}$ & \multirow{2}{*}{ Jumlah } & Persentasi (\%) \\
\cline { 3 - 4 } & & $\mathbf{1 0}$ & & \\
\hline \multirow{3}{*}{ II } & 10 & 21 & 21 & 87,5 \\
\hline & 5 & 1 & 1 & 4,17 \\
\hline & 0 & 2 & 2 & 8,33 \\
\hline
\end{tabular}

Tabel 16. Rekapitulasi Hasil TesSiklus II

\begin{tabular}{c|l|c}
\hline No & Keterangan & Nilai \\
\hline 1 & Nilai Tertinggi & 100 \\
\hline 2 & Nilai Terendah & 65 \\
\hline 3 & Nilai Rata-rata & 84,58 \\
\hline 4 & Ketuntasan Klasikal & 100 \\
\hline
\end{tabular}

Berdasarkan Tabel di atas dapat di simpulkan bahwa pada siklus II dengan jumlah siswa 24 orang dan dinyatakan tuntas semua diperoleh nilai rata-rata sebesar 84,58. Hal ini menunjukan adanya peningkatan hasil belajar siswa dari siklus I dan siklus II. Untuk melihat hasil angket respon siswa juga dapat dilihat pada Tabel sebagai berikut:

Tabel 17. Hasil angket respon siswa terhadap penggunaan metode pembelajaran Inside Outside Circle (IOC)

\begin{tabular}{|c|c|}
\hline \multicolumn{2}{|c}{ Respon Siswa } \\
\hline Ya & Tidak \\
\hline $97,92 \%$ & $2,08 \%$ \\
\hline
\end{tabular}


Berdasarkan Tabel 4.23 dapat dilihat dari persentasi siswa senang dengan menggunakan metode pembelajaran Inside Outside Circle (IOC) karena terlihat dari jumlah jawaban "Ya" terdapat 235 dari 210 atau jika dipersentasikan sebesar 97,92\% dan dari skor tersebut dapat dikatakan siswa sangat merespon dengan baik pembelajaran dengan menggunaan metode pembelajaran Inside Outside Circle (IOC) pada materi keseimbangan ekosistem.

\section{PEMBAHASAN}

\section{Observasi guru}

Observasi guru dapat dilihat dari pengolahan data yang mana diperoleh hasil pada siklus I pertemuan 1 diperoleh persentasi sebesar $90 \%$, pada siklus I pertemuan 2 diperoleh persentasi sebesar 95\%, pada siklus II pertemuan 1 dipeoleh persentasi sebesar 95\% serta pada siklus II pertemuan 2 diperoleh persentase sebesar 100\%. Penelitian ini diperkuat oleh penelitian yang dilakukan oleh Yustini, dkk (2012), dengan persentasi nilai $94,95 \%$ pada siklus I dan $100 \%$ pada siklus II, kegiatan guru dalam belajar sudah dikatakan sangat baik.

Meningkatnya kegiatan guru dikarenakan dalam tahapan ini guru sudah mengalokasikan waktu dengan baik, sehingga seluruh tahap-tahap pembelajaran dengan menggunakan metode Inside Outside Circle (IOC) sudah terlaksana. Meningkatnya kegiatan guru berperan serta dalam meningkatkan kegiatan siswa didalam belajar. Dengan demikian guru dikatakan mampu mengelola pembelajaran dengan menggunakan metode Inside Outside Circle (IOC) dengan efektif dan sangat baik.

\section{Observasi siswa}

Observasi siswa dapat dilihat dari pengolahan data, diperoleh hasil pada siklus I pertemuan 1 diperoleh persentasi sebesar $87,50 \%$, pada siklus I pertemuan 2 diperoleh persentasi sebesar $93,75 \%$, pada siklus II pertemuan 1 dipeoleh persentasi sebesar 93,75\% serta pada siklus II pertemuan 2 diperoleh persentase sebesar $100 \%$.

Penelitian ini sejalan dengan penelitian yang dilakukan Darmawati dkk (2012), dengan persentasi nilai sebesar $81,13 \%$ pada siklus I sedangkan pada siklus II sebesar $90,21 \%$. Karena padatahapan ini aktivitas siswadalam pembelajaran sudah terlihat sangat efektif atas bimbingan seorang guru di dalam kelas. Hal ini juga didukung oleh Yasa dalam Yustini (2012), yang menyatakan bahwa aktivitas guru juga mempengaruhi aktivitas siswa dalam mengikuti pembelajaran.

\section{Aktivitas belajar siswa}

Aktivitas belajar siswa dapat dilihat dari meningkatnya aktivitas belajar siswa dikarenakan pada tahapan ini indikator visual activities seperti membaca dan mengamati gambar dari siklus I dan siklus II mengalami peningkatan, pada indikator oral activities seperti bertanya dan menjawab pertanyaan siswa dari siklus I dan siklus II juga mengalami peningkatan, selanjutnya pada indikator listening activities seperti siswa memperhatikan saat berdiskusi dan aktif saat berdiskusi dari siklus I dan siklus II juga mengalami peningkatan, kemudian pada indikator emotional activities seperti siswa aktif dalam belajar, tidak bosan dalam belajar dan senang dalam mengikuti pembelajaran dari siklus I dan siklus II juga mengalami peningkatan. Aktivitas siswa dalam hal ini dipengaruhi oleh aktivitas guru, karena pada tahapan ini guru mampu mendorong siswa untuk memanfaatkan kesempatan beraktivitas secara tanggap, karena guru dalam belajar berperan sebagai motivator, pembeimbing serta fasilitator, Yasa (Yustini 2012).

Meningkatnya aktivitas belajar siswa pada indikator visual, oral, listening dan emotional juga dipengaruhi oleh pembelajaran dengan menggunakan metode 
pembelajaran Inside Outside Circle (IOC) yang menekankan kepada siswa agar saling bertukar informasi dengan baik dan berperan aktif dalam pembelajaran. Hal ini sesuai dengan pernyataan Lee (Yustini 2012), yang menyatakan metode pembelajaran Inside Outside Cirle (IOC) memungkinkan siswa untuk saling bertukar informasi yang berbeda dengan singkat dan teratur serta berperan aktif dalam belajar dapat meningkatkan aktivitas siswa dalam berkomunikasi dalam pembelajaran.

\section{Hasil belajar kognitif siswa}

Hasil belajar siswa dapat dilihat dari hasil prolehan nilai rata-rata pada siklus I sebesar 77,91 dan pada siklus II sebesar 84,58 . Peningkatan yang terjadi antara siklus I dan siklus II adalah sebesar 6,87.

Metode pembelajaran Inside Outside Circle (IOC) juga bagian dari pembelajaran kooperatif yang menuntut siswa selalu aktif dalam pembelajaran sehingga tercapailah tujuan belajar yang diinginkan. Trianto (2011: 41), menyatakan bahwa pembelajaran kooperatif muncul dari konsep bahwa siswa akan lebih mudah menemukan dan memahami konsep yang sulit jika mereka saling berdiskusi dengan teman sebayanya. Slavin dalam Rusman (2012: 201), juga menyatakan bahwa pembelajaran kooperatif menggalakkan siswa berinteraksi secara aktif dan positif dalam belajar, sehingga dapat meningkatkan hasil belajar siswa dan tercapailah tujuan pembelajaran yang diinginkan.

Meningkatnya hasil belajar kognitif siswa secara signifikan dipengaruhi oleh pembelajaran dengan menggunakan metode pembelajaran Inside Outside Circle (IOC) yang dapat menciptakan suasana belajar yang menyenangkan serta melatih kemampuan siswa dalam berkerja sama dalam mendapat materi yang berberda pada saat yang bersamaan dalam kelompoknya. Dengan cara inilah setiap siswa dapat memperoleh informasi, dan mengembangkan sendiri pengetahuannya. Proses pembelajaran yang banyak melibatkan siswa dalam belajar, akan bersifat menantang dan pada akhirnya siswa memiliki rasa ingin tahu yang sangat tinggi. Hal ini merupakan penggerak bagi keberhasilan siswa dalam belajar. Sardiman dalam Darmawati (2012).

\section{Angket respon siswa}

Angket respon siswa dapat dilihat secara keseleruhan diperoleh hasil respon siswa terhadap penggunakan metode pembelajaran Inside Outside Circle (IOC) untuk jawaban "Ya" sebesar 97,92\%. dan dari skor tersebut dapat disimpulkan bahwa siswa sangat merespon dengan baik pembelajaran dengan menggunaan metode pembelajaran Inside Outside Circle (IOC) pada materi keseimbangan ekosistem. Penelitian ini sejalan dengan penelitian yang dilakukan oleh Megawati dkk (2013), dengan persentasi sebesar $90 \%$, siswa telah merespon dengan sangat baik pembelajaran dengan menggunak metode pembelajaran Inside Outside Circle (IOC). Karena siswa merespon dengan baik pembelajaran dengan menggunakan metode pembelajaran Inside Outside Circle (IOC). Hal ini juga terlihat selama proses pembelajaran siswa sangat aktif dalam belajar dan didukung hasil angket yang telah diisi siswa setelah belajar menggunakan metode pembelajaran Inside Outside Circle (IOC).

\section{SIMPULAN}

Berdasarkan hasil penelitian dan pembahasan, dapat disimpulkan secara keseluruhan bahwa penggunaan metode pembelajaran Inside Outside Circle (IOC) untuk meningkatkan aktivitas belajar dan hasil belajar kognitif siswa adalah sebagai berikut: (1) Hasil kemampuan guru dalam mengelola pembelajaran dengan menggunakan metode pembelajaran Inside Outside Circle (IOC) mengalami peningkatan. Hal tersebut terbukti dari hasil pada siklus I pertemuan 1 diperoleh persentasi sebesar $90 \%$, pada siklus I 
pertemuan 2 diperoleh persentasi sebesar 95\%, pada siklus II pertemuan 1 dipeoleh persentasi sebesar 95\% serta pada siklus II pertemuan 2 diperoleh persentase sebesar $100 \%$; (2) Hasil kegiatan siswa dalam mengikuti pembelajaran dengan menggunakan metode pembelajaran Inside Outside Circle (IOC) mengalami peningkatan. Hal tersebut terbukti dari hasil pada siklus I pertemuan 1 diperoleh persentasi sebesar $87,50 \%$, pada siklus I pertemuan 2 diperoleh persentasi sebesar 93,75\%, pada siklus II pertemuan 1 dipeoleh persentasi sebesar 93,75\% serta pada siklus II pertemuan 2 diperoleh persentase sebesar 100\%; (3) Hasil aktivitas belajar siswa dalam mengikuti pembelajaran dengan menggunakan metode pembelajaran Inside Outside Circle (IOC) mengalami peningkatan. Hal tersebut terbukti dari hasil observasi siklus I pertemuan pertama, untuk yang menjawab "Ya" pada indikator visual activities sebesar $89,58 \%$, oral activities sebesar $54,17 \%$, listening activities sebesar $83,33 \%$. emotional activities sebesar $86,11 \%$. Siklus I pertemuan kedua untuk yang menjawab "Ya" pada indikator visual activities sebesar $91,67 \%$, oral activities sebesar $56,94 \%$, listening activities sebesar $83,33 \%$, emotional activities sebesar $84,44 \%$. Siklus II pertemuan pertama untuk yang menjawab "Ya" pada indikator visual activities sebesar 95,83\%, oral activities sebesar $72,22 \%$, listening activities sebesar 89,58\%, emotional activities sebesar 98,61\%. Selanjutnya pada siklus II pertemuan kedua hasil observasi aktivitas belajar siswa untuk yang menjawab "Ya" pada indikator visual activities sebesar $100 \%$, oral activities sebesar $80,55 \%$, listening activities sebesar 97,91\%, emotional activities sebesar 100\%; (4) Hasil belajar kognitif siswa dengan menggunakan metode pembelajaran Inside Outside Circle (IOC) mengalami peningkatan. Hal tersebut terbukti dari hasil prolehan nilai rata-rata pada siklus I sebesar 77,91 dan pada siklus II sebesar 84,58. Peningkatan yang terjadi antara siklus I dan siklus II adalah sebesar 6,87; (5) Hasil angket respon siswa dengan menggunakan metode pembelajaran Inside Outside Circle (IOC) menunjukan respon yang sangat baik. Hal tersebut terbukti dari persentasi jumlah siswa menjawab "Ya" sebesar $97,92 \%$.

\section{REFERENSI}

Azhari, Wira. (2012). "Hubungan Antara Aktivitas Belajar Dengan Hasil Belajar Siswa Pada Materi Sistem gerak Manusia Di Kelas VIII Sekolah Menengah Pertama Negeri 4 Sintang Tahun Pelajaran 2011/2014". Sintang Tidak diterbitkan. Sintang: STKIP Pesada Khatulistiwa Sintang.

Darmawati, Imam mahdi dan Ria Syafitri. (2012). "Penerapan Model pembelajaran Kooperatif Tipe Inside Outside Circle Untuk meningkatkan Sikap IImiah dan hasil Belajar Biologis Siswa Kelas VIII SMPN 2 Pekan Baru Tahun Pelajaran 2011/2012" Jurnal Biogenesis, 8 (2).

Megawati, Murdan dan Riastini (2014). "Pengaruh Model Pembelajaran Kooperatif Tipe Inside Outside Circle (loc) Terhadap Hasil Belajar Ipa SiswaKelas V Tahun Pelajaran 2013/2014 Di Gugus VIIKecamatanSawan"e-Journal MIMBAR PGSD Universitas Pendidikan Ganesha Jurusan PGSD 2 (1)

Ngalimun. (2016). “Strategi Dan Model Pembelajaran”. Yogyakarta: Aswaja.

Sugiyono. (2014). "Metode Penelitian Kuantatif, Kualitaitf dan R\&D”. Bandung: alfabeta.

Sutikno, Sobirin M. 2009. Belajar Pembelajaran "Upaya Kreatif dalam Mewujudkan Pembelajaran yang Berhasil". Bandung: Prospect. 
Rusman. (2012). "Model-model Pembelajaran: Mengembangkan Profesionalisme Guru" Jakarta: Rajawali Pers.

Trianto. (2011). "Model-model Pembelajaran Inovatif Berorientasi Kontruktivistik" Jakarta: Prestasi Pustaka.

Undang-undang Nomor 20 Tahun 2003 tentang sistem Pendidikan Nasional (2003: 3)

Yustini, Arnentis dan Yusika (2012)."Penerapan Model Pembelajaran Kooperatif Tipe Inside Outside Circle (loc) Dalam Meningkatkan Aktivitas Dan Hasil Belajar Biologi Siswa Kelas Viiia Smpn 2 Logas Tanah Darat Kabupaten Kuantan Singingi Tahun Pelajaran 2011/2012". Jurnal Biogenesis, 8(2). 